\title{
AC 2007-2497: FIRST YEAR ENGINEERING DESIGN: INCORPORATING LEADERSHIP DEVELOPMENT INTO REAL PROJECT EXPERIENCES
}

Kevin Sutterer, Rose-Hulman Institute of Technology

James Hanson, Rose-Hulman Institute of Technology

John Aidoo, Rose-Hulman Institute of Technology 


\title{
First Year Engineering Design: Incorporating Leadership Development into Real Project Experiences
}

\begin{abstract}
First year (freshman) engineering students often arrive on campus eager to begin designing engineered systems. Although their engineering design expertise is not nearly developed, the students themselves are often ready to begin. Some engineering student attrition can be attributed to students' disappointment with typical first and second year curricula rich in math, science, and humanities course work, but featuring only a course or two with direct engineering emphasis. The Department of Civil Engineering at Rose-Hulman Institute of Technology offers a 10 week course in which teams of four first year students complete a real engineering design for external clients. Projects are solicited from the region, selected based on student capabilities and workload, and mentored by the entire department faculty. The student teams interact directly with the client and produce a substantial final report comparable to a feasibility study and preliminary design. Example designs include bicycle trails, independent wastewater treatment systems, parks, athletic fields, and handicap access retrofits.
\end{abstract}

ASCE Policy Statement 465 calls for leadership training of civil engineering students. First year students are well suited for training on leadership, teaming, and professionalism. In the Department of Civil Engineering at Rose-Hulman, one aspect of leadership and teamwork training is Covey's The Seven Habits of Highly Effective People (1989). Application of the Seven Habits infiltrates the curriculum in various courses. Growth of students along Covey's maturity continuum would be comparable to leadership development as the students are motivated to seek interdependence. Over the past three years, Covey's Seven Habits have been incorporated into the weekly activities for student teams working on projects in this first year course. Student acceptance of the Seven Habits as a framework for self-improvement was mixed for the first few years. However, modification of the lessons to integrate application of the Habits to help the students with their client and group interaction has proven more successful. Assessment of perceived learning and development for this study through course surveys, course evaluations, and interviews indicates more students are embracing the Seven Habits as one tool to enhance their development as civil engineers. Even so, despite student acceptance of the Seven Habits as a useful framework, students reported they were not necessarily applying the principles to their lives.

This leadership and teamwork training continues to evolve in the first year course. Future improvements will include learning modules designed to demonstrate application of the Seven Habits to engineering consulting and design. This paper summarizes only the freshman year component of leadership training being designed to infiltrate the curriculum in the department. 


\section{Introduction}

Students at Rose-Hulman Institute of Technology declare their engineering major at the beginning of their freshman year. Thus, students who have declared a civil engineering major usually enter civil engineering-based courses as early as their first quarter on campus: Graphical Communications in the fall quarter; Computer Applications and GIS in the winter quarter; and Engineering Surveying I, Engineering Statics, and Introduction to Design in the spring quarter. Three of the four courses are oriented towards civil engineering technology. The fourth course, Introduction to Design, has been developed to provide the students with a real, open-ended, civil engineering design experience in their freshman year. Along with the design experience provided in the course, students also learn skills outside of design, including time management, report writing, teamwork, client relations, and ethics. This paper examines how Covey's The Seven Habits of Highly Effective People (1989) has been incorporated into the course to foster learning outside of engineering design. The knowledge, skills and attitudes imparted in this book and supporting materials will be referenced in the remainder of this paper as Seven Habits.

\section{Freshman Design Class Overview}

The course Introduction to Design is an Engineering Mechanics course required for most freshmen engineering students at Rose-Hulman. The 10 week course is two quarter credits, meeting once a week for 3 successive class periods. Each engineering department that requires the course offers at least one section targeted to their own students. There is no coordination of the course between disciplines, so each department defines the course makeup and activities to meet their curriculum. The Department of Civil Engineering typically offers two sections to civil engineering students, and the course content and learning objectives are significantly different from sections of the course offered in other departments on campus. The remainder of this paper will thus refer to the course as "CE Intro to Design" to distinguish the course discussed herein from other sections of the course offered by other departments.

Some of the course objectives are that, upon completion, the students should have the ability to employ leadership skills, communicate effectively, work productively in a team setting and undertake personal and professional development. $\mathrm{CE}$ Intro to Design has four main components:

- design of a real project for an outside client,

- a report of the design to the client,

- a one day trip to a major city to visit "big" civil engineering projects, and

- professional development training.

The fourth component is the subject of this paper, but a brief summary of the other three is appropriate to put the work reported in this paper into context.

Through friends in the community and open solicitation in the region, the department is able to arrange for a different project for each group of four freshmen taking the course. A freshman class of about 40 students thus requires 10 different projects. Students preference their project at the end of the winter quarter and are given their project assignments in week 1 of the spring quarter. Upon assignment of the project, the teams take immediate action to meet with their client and identify design needs. By week 2, the students have set up a rough work scope and 
schedule, and their design is under way. Because traditional engineering design knowledge is very limited at the freshman level, the projects typically involve a stronger emphasis on activities such as site layouts, simple treatment systems, trail designs, and a variety of preliminary design feasibility studies. Even so, all of the projects involve synthesizing a system of solutions to a design problem, utilization of suitable design references and codes, preparation of estimated construction costs, and documentation of findings in a formal report presented to the client at the end of the quarter. Many of the projects are eventually implemented by the clients. Several typical projects from the spring of 2006 include design of trail spurs, outdoor recreational facilities, sustainable student housing, and handicap access to a church basement. In addition to the instructors for the course, each team is assigned a faculty mentor other than the instructor. The student teams are to meet regularly with their faculty mentor for guidance on their work. Thus, all faculty in the department become involved with the freshman projects and the teams.

Although the project report could be perceived as a part of the project, the skills necessary to create a successful design do not necessarily translate into a successful report. Because the design is of limited value if it cannot be communicated, a significant portion of the learning in the course involves creation of the client report. Students learn to manage creation of site plans, engineering drawings, report tables and figures, and how to organize the material into a suitable engineering report. The instructors foster this learning through weekly assignments of portions of the report so the draft report submittal in week 8 consists of assembling together report sections prepared during the prior seven weeks.

The department believes a day trip to a major city is a good opportunity to expose our freshman to the work conducted by most civil engineers. The trip is also a good opportunity for the members of the class to get to know each other and begin to form a community of learners. Day trips are typically to St. Louis, Cincinnati, or Chicago since sites in Indianapolis are often accessed through other class field trips. Each of the typical cities visited is approximately 3 hours from campus while Indianapolis is only 1 hour away.

Professional development training is a strong emphasis in the department. Student success both during their college years and afterwards is improved if students are learning the professional aspects of the business while learning technical aspects and design process. Skills that are emphasized include teamwork, time management, client relations, continuing education, business communication, ethics, marketing, and technical presentation. All of these skills are required in the CE Intro to Design course, so weekly lesson plans include learning in these areas along with learning about report writing, engineering careers, and engineering design. The work reported in this report is the outcome of the department's desire to provide a common sense framework in which the students could begin to develop many of these important professional skills.

\section{Vision for Our Students - Development as Professionals}

Our department's program mission statement is "to provide an excellent civil engineering education that prepares graduates to meet the needs of their employers, clients, and community in a continually changing world." Therefore, we see the education process as more than just

transferring knowledge. It is the development of our students into professionals. Such 
development requires the transformation of attitudes and the adoption of new behaviors in addition to the acquisition of knowledge.

We strive to help our students become ...

- Self-motivated.

- Accountable for their actions.

- Confident communicators.

- Cooperative team members.

- Motivating leaders.

Developing as a professional is more than just mastering ABET outcomes a-k (ABET, 2006). Therefore, we decided that teaching "teams" skills was not enough. We also believe that students cannot become motivating leaders until they develop personal and leadership skills. Therefore, we, as instructors, must provide the environment, incentives, and knowledge for our students to adopt and affirm appropriate engineering behaviors and attitudes.

\section{Seven Habits of Highly Effective ... Civil Engineers?}

We found several articles that cover how to teach teamwork skills (e.g., Seat and Lord, 1999; Downing, 2001) but decided that focusing on teamwork skills without also focusing on personal skills would be fruitless. Many of the faculty in the department are former practitioners, and reflection on what makes a practitioner successful helped us recognize the same skills and attitudes increase our students' success in their course work. In fact, those skills and attitudes enhance personal and professional success in a myriad of ways. A review of books and resources to help us remind our students of the "common sense" skills and attitudes they should develop led us to adopt the framework and concepts of Covey's The Seven Habits of Highly Effective People (1989).

Covey's basic premise is that the Seven Habits are a natural extension of living a principlecentered life. His identification and classification of the Seven Habits came from a study of highly effective people throughout history. Therefore, the Habits appear to be timeless. The "Habits" can also be described as a blend of attitudes and skills demonstrated as routine behavior. Finally, from our perspective in the department, the principle-centered nature of the Habits also fosters ethical behavior.

The Seven Habits are the following (Covey, 1989):

1. Be proactive. This Habit describes an emphasis on focusing on the things one has influence over and not focusing on the things one cannot change. This includes taking responsibility for one's actions rather than considering oneself the victim.

2. Begin with the end in mind. This Habit emphasizes the importance of visualizing the end state before beginning. This can be applied to a person's life (personal mission statement) or a project (visualizing the final product).

3. Put first things first. This Habit is about acting on priorities. Everyone should choose how they spend their time based on their priorities.

4. Think win/win. This Habit emphasizes that in all important relationships (personal, business, etc.), each person should work to find a mutually beneficial arrangement. If such an arrangement cannot be found, no arrangement should be made. 
5. Seek first to understand, then to be understood. This is the Habit of empathy. Effective communication starts by understanding the other party's point of view.

6. Synergize. This Habit embodies the real goal of teamwork. As instructors, we want our teams to be able to accomplish more than the sum of what the individuals could have accomplished.

7. Sharpen the saw. This is the Habit of renewal. People cannot sustain these Habits without physical, social/emotional, mental, spiritual renewal.

The formal learning expected for civil engineers, as recently published in "Civil Engineering Body of Knowledge for the $21^{\text {st }}$ Century" (ASCE, 2004), includes 15 learning outcomes for formal engineering education. Of those 15 outcomes, seven are oriented to engineering design and technical knowledge, five map to the "Vision for Our Students - Development as Professionals" goals identified previously, and the remaining map to engineers as a part of the larger world community. The five professional outcomes are

- an ability to function on multi-disciplinary teams (4-6)

- an understanding of professional and ethical responsibility (1-3)

- an ability to communicate effectively (5)

- an understanding of management (1-7)

- an understanding of leadership principles and attitudes (1-7)

The numbers in parentheses are the habit numbers, as identified by Covey, corresponding to those professional outcomes. Although the department had identified Covey's work as a good starting point for the students' professional development prior to release of the ASCE report, we were pleased to see exceptional support for our learning reflected in the new ASCE Body of Knowledge.

One particular component of the ASCE Body of Knowledge that is still under development by ASCE is the "attitudes" part of the knowledge, skills, and attitudes required by civil engineering professionals to succeed. The final recommendations on the learning of attitudes is not yet prepared by ASCE, but we are confident the principle-centered Habits promoted by the Seven Habits should effectively coincide with many of the attitudes that will be identified by ASCE.

\section{Incorporation into the Course}

The timing of the learning of Seven Habits in the course has remained relatively consistent, though assignments relevant to the Seven Habits' learning have changed somewhat, as will be described later.

As noted previously, the class meets once every week for three successive 50 minute periods. The classroom lectures focus on team skills, project planning, problem solving techniques, and self development tools such as the Seven Habits. A typical day in class begins with introducing one of the Seven Habits in the first hour of class. This Habit is thoroughly explained and discussed with the students. The discussion could take the form of individual brainstorming or could involve a group activity. Emphasis is placed on how this Habit could result in a quality project report. Once the Habit topic for the week has been introduced, other class business has 
been resolved, and questions about the weekly assignment have been answered, the students are then set begin to work with their respective teams on their project designs. Assignments for the week include relevant reading material from Seven Habits, an on line quiz over the assigned reading, scheduled activities with the client and design team, and completion of a specified component of the report.

\section{Early Applications}

Initially, the Seven Habits instruction was conducted in parallel with and somewhat independent of the project. The first week was an introduction to the Seven Habits. One habit was discussed per week for the following seven weeks. Each discussion took approximately twenty minutes. Homework assignments ensured that students either read the book or listened to the CD version. Each homework assignment also had a component that challenged the students to reflect on how the Habit could be implemented in their own lives. The discussions and homework assignments did not, however, directly show how the Seven Habits could impact the students' projects.

\section{Later Applications}

As incorporation of the Seven Habits into the course evolved, it was found that students were more likely to accept the material as necessary to the class if the reading assignments could be translated into a team, report or client activity that had to be accomplished that week. The weekly Seven Habits assignments were thus mapped into as many of the project assignments as possible.

The following provides a brief overview of how the Seven Habits are effectively integrated into the weekly classroom activities and assignments.

Habit 1- Be Proactive. By proactive, Covey tells us that individuals are responsible for their actions. In any course of study, there are things beyond the control of the students, for example exams and assignment deadlines. However, the student has control over his or her response. The proactive student will consider the test dates and due dates and plan accordingly. Therefore, based on the first Habit teams are encouraged to assign project roles, assign specific tasks for each group member, contact their client and conduct a preliminary site visit. Deliverables from this Habit include a successful team meeting with the client to identify the project, a work plan and schedule for completion of activities identified by the students, and recommendations to the faculty for how the team will complete the project.

Habit 2- Begin with the end in mind. With Covey's second habit, students learn to plan the various tasks of the project keeping in mind the long term goals. Even with smaller tasks student learn that having short term goals makes them more productive. The key to motivation is having long-term goals. Deliverables from this habit include a detailed schedule for the work plan, a report introduction and a project description.

Habit 3- Put first things first. To introduce Habit 3, Covey uses a matrix to divide tasks into four quadrants (quadrants I, II, III and IV) depending on whether they are important, or not important and urgent or not urgent. Covey explains that to be very effective, one should not neglect Quadrant II tasks: tasks that are important but not urgent. This Habit was not as effectively mapped into the report schedule for week 3 because week 1 and 2 activities identified the work 
schedule, but learning about Habit 3 reminded the students to stay on task and set priorities. To reinforce Habit 3, teams are asked to fit the different sub-tasks of their project in any of the four quadrants. Through this group exercise each student comes to appreciate the essence of planning so that important tasks are not neglected. Students submit a Project Approach at the end of week 3 which re-emphasizes the learning of Habit 3.

Habit 4-Think Win-Win. The implication of this Habit is to get the teams focused on completing a project that will meet the clients' needs. In so doing, group members gain the experience of undertaking a real engineering project for an external client. Around week 4, the teams are asked to hold a second meeting with their client to discuss design options. During this meeting, it is not uncommon to have the client change their mind about their needs, to prefer a design the students have not favored, or to request additional work. It is also not unusual for the students to encounter challenges with the expectations of the instructor versus the mentor versus the client. The features of the Win/Win habit are crucial to managing these kinds of conflicts. Students do not have a report assignment that exercises this habit, but the lesson is learned by most groups through their interaction with their client, the instructor, and their faculty mentor.

Habit 5- Seek first to understand, then to be understood. Students are taught how to communicate effectively by listening empathetically. Naturally, there is the tendency to listen with the intent to reply but not to understand. Students are then asked to cultivate this habit in their regular client meetings. This leads to an effective and open discussion between the client and the students. Group members thus have a good grasp of the project requirements and are in a position to deliver a high quality report which will meet the client's expectations. During week 5, the student teams make their oral progress reports and obtain feedback from the client, the faculty members, and the other students. This feedback often has a significant impact on modifications to the project. Although the progress report would seem to be about being understood, the feedback from the audience is the focus of the lesson.

Habit 6- Synergize. At this stage students are strongly reminded to work as a team. The teams learn that the essence of synergy is to value differences, to build on strengths, and to compensate for weaknesses in any of the group members. Group members are advised to desist from behaviors that will be counter-productive to the goals of the team. They come to the realization that success of the team requires active participation of each group member. Week 6 is when the student teams begin to assemble their final report. This requires cooperation between all group members. Deliverables during this week and the week after include the estimated construction cost, design recommendations, and most of the figures and report front matter. Assembly of these work products requires significant collaboration. Instructors encounter numerous opportunities to remind team members with limited teaming experience to work particularly on implementation of Habits 4-6.

Habit 7- Sharpen the Saw. In the final lecture, students are advised to adopt the common senses that is organized into the Seven Habits for lifelong learning. By relating this to the concept of continuous learning, students are encouraged to consider pursuing graduate studies and personal professional development. Other than the assigned reading, students are not assigned additional work related to this Habit because they are very busy with design recommendations and final report preparation. 


\section{Findings}

Whether students are internalizing the Seven Habits is being measured by annual surveys summarized below. In addition, the course instructors have remained attentive to how the students accept this additional learning in a course that is already perceived by the students to be more time consuming than the credit hours would indicate. Seven Habits was incorporated as the course text in the Spring of 2003. The previous course text was a popular "coffee table" book about civil engineering that includes lots of pictures. The text was always highly rated for the course. The first year that Seven Habits was incorporated into CE Intro to Design, one instructor requested the written text of Seven Habits, while the other requested the students listen to the CD version. One instructor was a strong proponent of Seven Habits and the other was a skeptical supporter of "giving it a try." For this paper, the authors reviewed the student evaluation forms from spring 03-04, spring 04-05, and spring 05-06 for evidence of student perceptions about the learning material. No specific measure of student perceptions was obtained, but some students provided written comments about the material. Therefore, the number of occurrences of positive feedback and negative feedback in the comments for each section are tabulated in Table 1, after which some sample negative and positive comments by the students are provided. A sampling of student comments follows Table 1.

Instructor "KGS" was the skeptical first year instructor of Seven Habits. KGS was also the instructor who required a text rather than CDs for the course reading. It is apparent from the data that some of the students detected that skepticism or were more dissatisfied with the text. Even so, as instructor KGS has continued to use the Seven Habits in the class, he has become a stronger supporter of the material. It is possible this is the reason for the improvement in student perceptions after the first year. Instructors JHH and JAA received stronger positive response, or at least neutral response, from the inclusion of Seven Habits in their courses. Both instructors were stronger supporters of the material than KGS in their first year using the text.

\begin{tabular}{|c|c|c|c|c|}
\hline Instructor & Comment type & Spring 0304 & Spring 0405 & Spring 0506 \\
\hline KGS & $\begin{array}{c}\text { positive } \\
\text { negative } \\
+/-\end{array}$ & $\begin{array}{c}2 \\
7 \\
0.3\end{array}$ & $\begin{array}{c}3 \\
4 \\
0.8\end{array}$ & $\begin{array}{c}6 \\
3 \\
2.0\end{array}$ \\
\hline JHH & $\begin{array}{c}\text { positive } \\
\text { negative } \\
+/-\end{array}$ & $\begin{array}{c}1 \\
1 \\
1.0 \\
\end{array}$ & $\begin{array}{c}4 \\
1 \\
4.0 \\
\end{array}$ & \\
\hline JAA & $\begin{array}{c}\text { positive } \\
\text { negative } \\
+/-\end{array}$ & & & $\begin{array}{c}3 \\
3 \\
1.0\end{array}$ \\
\hline Overall & $\begin{array}{c}\text { positive } \\
\text { negative } \\
+/-\end{array}$ & $\begin{array}{c}3 \\
8 \\
0.4\end{array}$ & $\begin{array}{c}7 \\
5 \\
1.4\end{array}$ & $\begin{array}{c}9 \\
6 \\
1.5\end{array}$ \\
\hline \multicolumn{2}{|c|}{ No. Students Both Sections } & 46 & 43 & 39 \\
\hline
\end{tabular}


Some comments considered negative included

- "The 7 habits thing was kind of impractical."

- "Get rid of the seven habits."

- "The 7 Habits CDs need to go, they are not appropriate for the class. They are common sense and don't need to be taught in the classroom, let alone be assigned as required reading/listening."

- "I didn't enjoy the Seven Habits."

Some comments considered positive included

- "Great experience, a student will learn a lot, 7 Habits were extremely helpful, finally some real-life engineering."

- "...although a lot of people complain about the Steven Covey thing, it has a lot of good stuff in it."

- One identified strength of the course was "It was taught in conjunction with the seven habits."

- A student identified a high level of learning "Because of all the real world expereince we got from the project and the team building we learning through the "7 habits of highly effective people" homeworks."

Survey Results

In order to measure the impact on student behavior, we conducted pre- and post-surveys. The students take the survey on the first day of CE Intro to Design. The students then take the same survey almost a year later during their sophomore year. The first eight questions are shown in Table 2. Student responses are given a rating: "Always" $=4$, "Often" $=3$, "Seldom" $=2$, and "Never" $=1$. Table 2 shows the question, associated Habit number, and average rating for the pre- and post-surveys for the group. Each group consisted of at least 34 responses. Note that for some questions, such as "How often do you study alone?", a low average rating indicates behavior more consistent with the Habit. Such questions are denoted with a prime on the Habit number. Table 3 contains the next nine questions which focus on experiences when working with teams. Those student responses have the same rating system as in Table 2. The last three questions ask students to choose between activities (Table 4). The results are presented as percent of respondents who chose the designated activity.

Table 2. Summary of average student response to survey questions asked before CE Intro to Design and nearly one year later $(4=$ always, $1=$ never $)$.

\begin{tabular}{lcccc}
\multicolumn{1}{c}{ How often do you practice the following? } & Associated & & & \\
& Habit & $2004-2005$ & $2005-2006$ & $2006-2007$ \\
\hline Spend time thinking about things over which I have no control. & $1^{\prime}$ & $2.5 / 2.7$ & $2.7 / 2.5$ & $2.6 / 2.7$ \\
Work on my assignments at least 48 hours before they are due. & 1 & $2.4 / 2.4$ & $2.7 / 2.5$ & $2.4 / 2.5$ \\
Choose elective courses that will enhance my career. & 2 & $3.0 / 3.0$ & $3.0 / 3.0$ & $3.2 / 3.0$ \\
Sacrifice activities that are important to me due to urgent demands. & 3 & $2.7 / 2.8$ & $2.8 / 2.7$ & $2.7 / 2.7$ \\
Participate in service activities when time permits. & 4 & $2.7 / 2.4$ & $2.7 / 2.5$ & $2.6 / 2.7$ \\
Study alone. & $4^{\prime} \& 66^{\prime}$ & $3.0 / 3.0$ & $3.0 / 3.1$ & $2.9 / 3.1$ \\
Participate in activities that improve my overall physical health. & 7 & $3.2 / 3.0$ & $3.3 / 3.3$ & $3.3 / 3.0$ \\
Read non-fiction works in my spare time. & 7 & $2.0 / 1.9$ & $2.0 / 2.0$ & $2.1 / 2.0$
\end{tabular}


Table 3. Summary of average student response to survey questions about team project experiences asked before CE Intro to Design and nearly one year later $(4=$ always, $1=$ never $)$.

\begin{tabular}{|c|c|c|c|c|}
\hline $\begin{array}{c}\text { How often do you experience the following when working on team } \\
\text { projects or assignments? }\end{array}$ & $\begin{array}{c}\text { Associated } \\
\text { Habit } \\
\end{array}$ & 2004-2005 & 2005-2006 & $2006-2007$ \\
\hline I demonstrate enthusiasm about the project to team members. & 1 & $2.8 / 2.8$ & $3.0 / 3.0$ & $2.8 / 3.1$ \\
\hline I help team members develop a clear understanding/picture of the & & & & \\
\hline final project. & 2 & $2.7 / 3.1$ & $2.9 / 3.0$ & $2.9 / 3.0$ \\
\hline I help prioritize what needs to be done for the team. & 3 & $2.9 / 3.1$ & $2.9 / 3.1$ & $2.9 / 3.0$ \\
\hline $\begin{array}{l}\text { I encourage that everyone on the team receives an opportunity to } \\
\text { fulfill a "role" of their choice. }\end{array}$ & 4 & $30 / 30$ & 31 & $30 / 31$ \\
\hline I perform a disproportionately large share of the work. & $\begin{array}{l}4 \\
4^{\prime}\end{array}$ & $\begin{array}{l}3.0 / 3.0 \\
2.6 / 2.6\end{array}$ & $\begin{array}{l}3.1 / 3.1 \\
2.6 / 2.5\end{array}$ & $\begin{array}{l}3.0 / 3.1 \\
2.6 / 2.5\end{array}$ \\
\hline I listen carefully to what others are saying to better understand their & & & & \\
\hline point of view. & 5 & $3.2 / 3.3$ & $3.5 / 3.3$ & $3.4 / 3.3$ \\
\hline I mediate conflict among team members. & 5 & $2.7 / 2.5$ & $2.8 / 2.6$ & $2.7 / 2.6$ \\
\hline $\begin{array}{l}\text { I actively seek out the ideas of other team members regarding their } \\
\text { approach to solving a problem. }\end{array}$ & 6 & $3.1 / 3.1$ & $3.2 / 3.2$ & $3.1 / 3.1$ \\
\hline $\begin{array}{l}\text { I would have produced a better project as an individual than the } \\
\text { team did as a whole. }\end{array}$ & $6^{\prime}$ & $2.2 / 1.9$ & $2.2 / 2.0$ & $2.2 / 2.1$ \\
\hline
\end{tabular}

Table 4. Summary of student choices in response to survey questions asked before CE Intro to Design and nearly one year later.

\begin{tabular}{|c|c|c|c|c|}
\hline If given the choice, I would rather ... & $\begin{array}{c}\text { Associated } \\
\text { Habit }\end{array}$ & 2004-2005 & 2005-2006 & 2006-2007 \\
\hline Receive an average grade in a class where I learned a lot rather & & & & \\
\hline than receive a good grade in a class where I learned little. & 1 & $67 \% / 61 \%$ & $90 \% / 81 \%$ & $85 \% / 65 \%$ \\
\hline $\begin{array}{l}\text { Spend one hour playing my favorite sport rather than spend one } \\
\text { hour watching my favorite TV show. }\end{array}$ & 7 & $81 \% / 78 \%$ & $93 \% / 88 \%$ & $88 \% / 74 \%$ \\
\hline Spend time engaged in meaningful conversation with a friend & & & & \\
\hline rather than go to a party with a friend. & 7 & $47 \% / 53 \%$ & $69 \% / 64 \%$ & $59 \% / 74 \%$ \\
\hline
\end{tabular}

\section{Faculty Reflection}

The survey results show no systematic change in self-reported attitude and behavior. However, the comments from students in the course tended to be positive. The lack of change in the data suggests either (1) the questions do not accurately the potential changes in behavior that occurred, (2) the students who consider the instruction helpful were already using the Habits although they might not have been previously exposed to Covey's work, or (3) the current lessons for integration of the Seven Habits has little effect on student attitudes and behavior. It is possible that once students depart school, they begin to internalize these habits.

When Seven Habits was originally adopted by the faculty members, the decision was based more on judgment than supporting data. In such cases, it is prudent to measure outcomes to ascertain whether the learning objectives were achieved. This was the reason the survey data reported herein was acquired. At that time, limited effort was placed on studying the learning domains and nature of the questions being asked in the survey. In retrospect, more careful examination of the questions asked in the survey indicated a focus on a high level of learning in the Bloom's Affective domain (Krathwohl, et al., 1964). The five levels of Affective learning are (1) receiving, (2) responding, (3) valuing, (4) organization, and (5) characterization by a value 
complex. Most of the survey questions were focused somewhere at level 4 or level 5 in the Affective Domain wherein the learner has organized, adopted, and put into practice knowledge they have come to value. It is clear from some of the data from surveys and class evaluations that while a significant number of students value the knowledge acquired (level 3), they may not have adopted or put fully into practice what they have learned. To expect early learning at such a high Affective level based on material presented in only one class is unrealistic. It is clear that future assessment should better target learning at lower levels in the Affective domain.

\section{Conclusions}

While several years of integrating the Seven Habits with real engineering projects in CE Intro to Design have not produced measurable changes in student behavior (Affective levels 4 and 5), student comments suggest that many believe in the usefulness of the habits (Affective level 3). If students internalize the Seven Habits, they should make good advances in developing into the effective professionals. Therefore, the department is reviewing the assessment tool and investigating ways to change implementation that will have a lasting impact. Some ideas being explored include (1) integrating the Habits with course projects throughout the curriculum (habits can generally only be formed over time, through repetition), (2) making the associated attitudes and behaviors something that is assessed as part of course grades (change often occurs only when the discomfort of remaining unchanged is more than the discomfort of the change), and (3) further modifying the lessons in the CE Intro to Design course to help the students better understand how the principles in this learning module can benefit them professionally.

\section{References}

ABET, 2006, "Criteria for Accrediting Engineering Programs: Effective for Evaluations During the 2007-2008 Accreditation Cycle," Engineering Accreditation Commission, retrieved January 17,2007 from www.abet.org/forms.shtml .

ASCE, 2004, "Civil Engineering Body of Knowledge for the $21^{\text {st }}$ Century: Preparing the Civil Engineer for the Future," Body of Knowledge Committee of the Committee on Academic Prerequisites for Professional Practice, retrieved January 17, 2007 from www.asce.org/professional/educ/bodyofknowledge.cfm .

Covey, S. R., 1989, The Seven Habits of Highly Effective People: Restoring the Character Ethic, Simon and Schuster, New York, NY, 340 p.

Downing, C. G., 2001, "Essential Non-Technical Skills for Teaming," Journal of Engineering Education, Vol. 90, No. 1, Jan., pp. 113-117.

Krathwohl, D.R.; Bloom, B.S.; Masia, B.B; 1964, Taxonomy of Educational Objectives: The Classification of Educational Goals. Handbook II: Affective Domain, Longman, New York.

Seat, E. and Lord, S. M., 1999, "Enabling Effective Engineering Teams: A Program for Teaching Interaction Skills," Journal of Engineering Education, Vol. 88, No. 4, Oct., pp. 385-390. 